\title{
Arts and Humanities Literature: Bibliometric Characteristics of Contributions by Turkish Authors
}

\author{
Umut Al \\ Department of Information Management, Hacettepe University, 06532 Beytepe, Ankara, Turkey. \\ E-mail: umutal@hacettepe.edu.tr \\ Mustafa Şahiner \\ Department of English Language and Literature, Hacettepe University, 06532 Beytepe, Ankara, Turkey. \\ E-mail: msahiner@hacettepe.edu.tr \\ Yaşar Tonta \\ Department of Information Management, Hacettepe University, 06532 Beytepe, Ankara, Turkey. \\ E-mail: tonta@hacettepe.edu.tr
}

\begin{abstract}
Scholarly communication in arts and humanities differs from that in the sciences. Arts and humanities scholars rely primarily on monographs as a medium of publication whereas scientists consider articles that appear in scholarly journals as the single most important publication outlet. The number of journal citation studies in arts and humanities is therefore limited. In this article, we investigate the bibliometric characteristics of 507 arts and humanities journal articles written by authors affiliated with Turkish institutions and indexed in the Arts \& Humanities Citation Index $(\mathrm{A} \& \mathrm{HCl})$ between the years 1975-2003. Journal articles constituted more than $60 \%$ of all publications. One third of all contributions were published during the last 4 years (1999-2003) and appeared in 16 different journals. An overwhelming majority of contributions (91\%) were written in English, and $83 \%$ of them had single authorship. Researchers based at Turkish universities produced $90 \%$ of all publications. Two thirds of references in publications were to monographs. The median age of all references was 12 years. Eighty percent of publications authored by Turkish arts and humanities scholars were not cited at all while the remaining 20\% (or 99 publications) were cited 304 times (an average of three citations per publication). Self-citation ratio was $31 \%$. Two thirds of the cited publications were cited for the first time within 2 years of their publications.
\end{abstract}

\section{Introduction}

Garfield (1980a) pointed out that research and scholarly communication in sciences differ in many respects from that in the arts and humanities. "In contrast to scientists' study of

Received November 30, 2004; revised May 10, 2005; accepted May 16, 2005

(C) 2006 Wiley Periodicals, Inc. • Published online 13 April 2006 in Wiley InterScience (www.interscience.wiley.com). DOI: 10.1002/asi.20366 the physical universe, humanists are concerned with those human achievements which make up our cultural heritage. The works of art, religion, and philosophy which comprise this legacy are not superseded as scientific works are" (p. 42). Humanistic scholarship is "cumulative and least susceptible to obsolescence" (Stern, 1983, p. 205). Garfield (1980a) noted that "... humanities scholars are less compulsive about the literature than scientists are" (p. 43) and gave an example:

\footnotetext{
If a scientist discovered, say, the structure of DNA, and published an article about it, there is nothing other scientists can do about it whereas if a music scholar published a monograph on Bach, "you do not burn your manuscript. You know that no one (including yourself) will ever be able to say the last word about Bach and his music. (p. 43)
}

He also noted that arts and humanities scholars prefer books over journal articles as medium of publication and that

the citation tradition in the humanities is not as strong as it is in the sciences. An art historian may not formally cite such works as Guernica or the Mona Lisa. A literary critic would not cite Shakespeare everytime he mentions Hamlet. (p. 44)

Garfield first envisioned the use of citations listed in the bibliographies of articles to make connections between citing and cited works, and later founded the Institute for Scientific Information (ISI, now Thomson Scientific), which has been publishing the well-known and widely used Science Citation Index (SCI), the Social Science Citation Index (SSCI) and the Arts \& Humanities Citation Index (A\&HCI) since then. Citation indexes list documents that have been 
cited and the sources of these citations. Citation indexes also are useful for information retrieval and literature search. They can help researchers find relevant publications, keep up to date with relevant research, and eliminate the duplication of prior research. They also are used to evaluate the productivity of researchers, institutions, or nations and the relative importance of works in question by providing various citation statistics (journal impact factors, immediacy index, obsolescence rates, etc.). In line with the increasing number of publications, the $S C I$ covers over 5,900 science and technical journals while the SSCI lists the contents of 1,700 social sciences journals today. The $A \& H C I$, which forms the basis of this study, covers over 1,130 leading arts and humanities journals representing the fields of literature, art, architecture, archaeology, music, religion, classics, philosophy, history, dance, folklore, film, television, radio, linguistics, philology, and theater (Garfield, 1980a; İnönü, 2003; ISI, 2004a).

Garfield (1980a) described in detail how they developed the $A \& H C I$ for the arts and humanities scholars, its indexing principles, and the difference between the $A \& H C I$ and other citation indexes. The $A \& H C I$ indexes not only the journal articles but also "reviews of books, theater, opera, music and dance performances, recordings, and arts shows .... editorials, interviews, discussions, notes, letters, bibliographies, chronologies, corrections, errata, original poetry, short stories, essays, plays, and book excerpts" (p. 45). It "also covers individually selected, relevant items from over 7,000 science and social sciences journals" since 1979 (Garfield, 1980a, p. 45; ISI, 2004b).

The citation indexing of arts and humanities publications is somewhat different from that of sciences and social sciences. As such publications may contain reproductions of paintings or music scores, or mention novels and dance performances, without actually formally citing those works, they are treated by ISI indexers as "implicit" citations and indexed accordingly (Garfield, 1980a). When a citing article includes a work of art, a portion of a musical score, or contains an implicit citation not listed in its bibliography or footnotes, the A\&HCI displays the abbreviations of "ILL," "MUS," and "IMP," respectively, as the cited volume (ISI, 2004c; Stern, 1983). ISI indexers also add new terms (in parentheses) to the original source titles "that clarify, add meaning or supply search access points that would otherwise not exist." Such "title enhancements," as they are called, are a unique feature of the $A \& H C I$ (ISI, 2004d).

\section{Literature Review}

The availability of ISI's citation indexes made it possible to carry out a wide range of bibliometric and scientometric studies based on bibliometric characteristics of publications and references therein. Some of these works deal with scientific productivities of countries (Haiqi \& Yuhua, 1997; İnönü, \& Kurnaz, 2002; Jacobs \& Ingwersen, 2000; Moed, 2002; Moed, De Bruin, \& Van Leeuwen, 1995; Ortiz-Rivera, Sanz Casado, \& Suárez-Balseiro, 2000; Osareh \& Wilson, 2000; Uzun \& Özel, 1996; Wilson \& Osareh, 2003). Others make comparisons between countries in terms of their contributions to the world's overall scientific productivity (Braun, Glänzel, \& Grupp, 1995a, 1995b; Garfield, 1983). The great majority of citation-analysis studies concentrate on scholarly articles that appear in science and social science journals whereas relatively fewer citation studies are carried out in arts and humanities. The main reason for this is that different scientific disciplines have somewhat different scholarly communication modes and that citations serve different functions.

Arts and humanities scholars "prefer to work alone, and ... do their research on their own" (Buchwald, 1999). They publish books predominantly whereas books as a medium of scholarly communication are neglected by scientists (Hicks, 2004). Hicks (2004) reviewed the bibliometric studies of social sciences and humanities and found that scholars in these disciplines publish in four distinct literatures (journal articles, books, national literatures, and nonscholarly literature), each serving a different purpose. As Hicks suggested, the citation behaviors of scientists, social scientists, and arts and humanities scholars also are different. "In the humanities, referencing is archival (de Solla Price, 1970) and citation counts accumulate at a geological rate from the perspective of policy makers" (Hicks, 2004, p. 473).

Books as a medium of publication play a more important role in the humanities and social sciences (e.g., Garfield, 1980a, 1982a). Lindholm-Romantschuk and Warner (1996) studied the diffusion of ideas in the humanities and social sciences through citation analysis in monographic publications. They selected a sample of 116 single-authored monographs from philosophy, sociology, and economics published between 1973 and 1990, and identified citations to them through the $A \& H C I$ and the SSCI. They also identified citations to the journal articles written by the very same authors within a period of 5 years starting with the publication year of the monograph of each author. They hypothesized that "[i]n selected disciplines the scholarly monograph has a greater impact (as indicated by subsequent citations) than journal articles" (p. 394). Lindholm-Romantschuk and Warner analyzed the dataset and found that scholarly monographs generate 7.7 times more citations than journal articles written by the same authors in philosophy, 2.6 times in sociology, and 2.4 times in economics (p. 395). Such findings indicate that "... social and human sciences tend to have different communication patterns from the natural, physical and mathematical sciences. For instance, they can be less formalized in their communication patterns and monographic publication may have greater significance" (LindholmRomantschuk \& Warner, 1996, p. 391).

Similar findings were reported by other researchers as well. Stern (1983) found that about $80 \%$ of the references contained in source articles on literary movements and creative writings were to books while about $15 \%$ were to journal articles. This indicates that literary scholars make use of monographs much more often than journal articles. Heinzkill (1980) studied the distribution of 9,556 citations contained in articles published in English literary journals 
and obtained similar results (75\% to books, $20 \%$ to journal articles, and 5\% to other material). Cullars (1992) found that citations to journal articles in the fine arts literature constitute $23.6 \%$ of all citations while monographs constitute $60.6 \%$ and manuscripts $14.8 \%$. "Broadus (1971) found that books received about 60 to $70 \%$ of all citations in disciplines in the humanities like music, philology, and fine arts, 30 to $60 \%$ in various social sciences, and below $10 \%$ in some natural sciences" (as cited in Nederhof, Zwaan, De Bruin, \& Dekker, 1989). Hicks (2004) cited several studies in which it was found that books received more citations than that of journal articles in various disciplines of social sciences. Yet books are not fully covered by citation indexes, making evaluation of such works more difficult (Hicks, 2004). Although books constitute "a relatively small percentage of output, they account for a substantial proportion of citations in the $S S C I$-as much as $40 \%$. Indicators built from the $S S C I$ indexed material- journal articles and citations to themwill miss the $40 \%$ of citations received by books" (Hicks, 2004, p. 474). Therefore, performance evaluation studies based on the citation characteristics of publications in the arts and humanities and social sciences tend to be less reliable than those of sciences.

Nederhof et al. (1989) compared the use of bibliometric indicators in the humanities and social sciences. They studied the publications of Dutch scholars in the humanities (social history, general linguistics, general literature, Dutch literature, and Dutch language) and social and behavioral sciences (experimental psychology, anthropology, and public administration) to test the hypotheses that (a) books are more important as a medium of publication, and (b) scholars write mainly for the local public in these disciplines. They found that humanities scholars publish scholarly articles as well as popularizing articles which serve to enlighten the public.

Book reviews also are important in the arts and humanities. Journals contain several book reviews. In her dissertation work, Lindholm-Romantschuk (1994) studied "an elite sample of scholarly monographs published by university presses 1971-1990" and found that "book reviews were significant indicators of scholarly communication and that they can be successfully used to trace flows of information within and across knowledge domains" (as cited in LindholmRomantschuk \& Warner, 1996, p. 391). Stern (1983) also observed that book reviews make up the large proportion of the literature of literary scholarship, indicating the "bookoriented nature" of the field (p. 203).

The $A \& H C I$ indexes book reviews contained in the arts and humanities journals. Garfield (1982a) noted that book reviews constitute more than $40 \%$ of the articles indexed in the $A \& H C I$, although they get, on average, much fewer citations than journal articles. A journal article gets cited, on average, more than 18 times whereas a book review does 1.4 times (Garfield 1982a). Hicks (2004) found "little overlap between books that were reviewed and cited. When asked, historians responded that reading a book is the best way to evaluate it, followed by reading a review and then by number of citations" (p. 476).
Nederhof and Zwaan (1991) studied whether some journals can be considered "core" in the humanities. They found that many humanities fields are characterized by "core" journals similar to journals in science and engineering. They noted that the use of citation-based assessment of literature in nationally oriented subjects or in languages other than English may not be the best option as they are not internationally oriented fields. Heinzkill (1980) found that some journals can be considered "core" in English literature and noted that "50 percent of the citations came from 19 journals, 61 percent came from 33 journals, yet the distribution of citations did not produce the Bradford curve" (p. 357). The Bradford curve "describes how the literature on a particular subject is scattered or distributed in the journals" (Garfield, 1980b, p. 5).

Heinzkill (1980) also found that the recency of articles is not as important in English literature as it is in the sciences. "The past ten years satisfied about 40 percent of the journal demand while 71 percent of the citations were satisfied by journals published since $1945 \ldots$... By contrast, in the sciences 70-90 percent of the journal use is of journals appearing within the past ten years" (Heinzkill, 1980, p. 360). Similarly, fine arts journals obsolesce much more slowly than those in the sciences and social sciences (Cullars, 1992). Cullars (1992) concluded that:

The highly interdisciplinary nature of scholarship in the fine arts suggests that any attempt to build a core library collection of fine arts sources based mainly on citation data would be a misguided endeavor. The very wide chronological span of cited sources further suggests that the weeding of older materials is more problematic than in many other disciplines and that retrospective purchases should be encouraged. (p. 341)

As scholarly communication patterns and citation behaviors of arts and humanities scholars tend to differ from those of scientists and social scientists, performance evaluation studies based on citation analysis in these fields have been questioned. The majority of professors in the humanities in Germany thought that "problem of quality cannot be tackled with quantitative methods" (Finkenstaedt, 1980, p. 410). Finkenstaedt (1980) noted that some disciplines in the humanities such as regional studies, local history, and teacher training do not address an international audience and thus "have a limited range as far as output and impact are concerned, but it would be ridiculous to rate such subjects lower than the sciences" (p. 414). He emphasized the need for "a more comprehensive study of the overall citation behaviour in the humanities" (p. 415) and noted that "[i]n the humanities we cannot expect a natural survival of the fittest" (p. 416).

Problems of citation analysis are well known. MacRoberts and MacRoberts (1989) cited no less than seven major problems (e.g., biased citations and self-citations, omissions, variations in citation rate related to type of publication, nationality, time period, size and type of specialty). In a more recent study, Nederhof, Luwel, and Moed (2001) assessed the quality of scholarly journals in linguistics by means of 
non-citation-based measures, which, they thought, provide "an alternative to research performance assessment based exclusively on ISI citation indices" (p. 264). Because they thought that the ISI-based citation measures cannot be used successfully in nationally oriented subjects or in languages other than English, they decided to use a questionnaire to identify the quality scholarly journals in the humanities disciplines by asking 295 scholars in linguistics. The sample was selected from among all the linguistics scholars worldwide. They found that "a large part of the publications deal with nationally oriented topics rather than with 'cosmopolitan' topics as in the natural and life sciences; frequent use is made of national language(s) rather than English; an important part of the publication occurs in local outlets rather than in internationally refereed journals; journals are less important than in natural and life sciences; coverage of journals in ISI's Citation Indices is unsatisfactory" (Nederhof et al., 2001, p. 241-242).

Hérubel and Buchanan (1994) published a selective and annotated bibliography on citation studies in the humanities and social sciences which covers journal articles, theses, proceedings, book chapters, and monographs.

Citation-based performance evaluation studies also have been carried out in Turkey. Using mainly ISI's citation indexes, Turkey's contribution to the world's scholarly literature in sciences, medicine, and social sciences has been studied and compared with other countries within the last 15 years (Denkel, Kâğıtçıbaşı, Pak, \& Pamuk, 1996, 1999; Garfield, 1991; Gülgöz, Yedekçioğlu, \& Yurtsever, 2002; Tonta, 2000; Tonta \& İlhan, 1997; Uzun, 1996, 1998; Yurtsever, Gülgöz, Yedekçioğlu \& Tonta, 2001, 2002). Although these works have provided information about Turkey's contribution to the world literature and have given bibliometric features of publications, no research has so far been carried out on bibliometric characteristics of publications authored by the arts and humanities scholars affiliated with Turkish institutions.

\section{Method}

This study aims to investigate the performance of the Turkish arts and humanities scholars by carrying out a bibliometric study (number of authors, authors' affiliations, journals, etc.) and a citation analysis of their publications that have appeared between 1975 and 2003. The following research questions were addressed:

1. What is the distribution of publication types (e.g., monographs, journal articles, book reviews, etc.) authored by Turkish arts and humanities scholars?

2. In which journals do Turkish arts and humanities scholars publish more often?

3. Is there a core list of journals that publish contributions by the Turkish arts and humanities scholars?

4. Is the single authorship prevalent in the arts and humanities publications?

5. What types of sources (e.g., monographs, journal articles, book reviews, etc.) get cited more often in the arts and humanities literature?
6. What is the median age (i.e., half-life) of the cited references in the arts and humanities publications?

7. What percentage of publications authored by Turkish arts and humanities scholars gets cited, how often, and by what types of publications?

8. How long does it take for publications authored by Turkish arts and humanities scholars to get their first citations?

The ISI's $A \& H C I$ database, available through Thomson's Web of Science (WoS), was used to identify publications. In this study, the term "publication" is defined, unless otherwise indicated, as journal articles, book reviews, meeting abstracts, notes, and so on that were authored by the arts and humanities scholars affiliated with Turkish institutions and included in the $A \& H C I$ database. The term "contribution" was sometimes used interchangeably with "publication" throughout the text. Similarly, "arts and humanities scholars affiliated with Turkish institutions" were sometimes loosely referred to as "Turkish authors" or "Turkish scholars." To identify publications in the database, an online search was performed on November 12, 2003, using the "address" field that is available. To obtain reliable data, different forms (including abbreviations) of Turkish addresses in different languages (e.g., "Turkey," "Türkei," "Turquie," "Turkish") were entered in the address field. A total of 507 such publications were identified. Each record provided information about the author name(s), author address(es), journal name, publication year, language, document type, number of references included in the publication, and the number of citations that the publication received as of November 12, 2003. Separate files were created for author names, journal names, and author addresses of all the 507 publications. Addresses that belonged to the same institution, but entered in different forms or in different languages (e.g., "Bogazici Univ" and "Bosphorus University" refer to the same university, the former being in Turkish), were treated as the same and classified accordingly. As the address field of the A\&HCI database was used to identify publications, a few foreign authors who at the time worked for Turkish universities or research centers were identified during the search. If the foreign author was the sole contributor of a publication, such cases were excluded from the final count. The affiliation addresses of the first authors and joint authors were counted separately, and the institutions were credited accordingly. The SPSS (Statistical Package for Social Sciences) and Microsoft Excel were used to evaluate the data.

The distribution of publication types (e.g., monographs, journal articles, book reviews, etc.) and the number of contributing authors were identified along with the journal names that contained the highest number of publications authored by Turkish arts and humanities scholars. References contained in the arts and humanities source publications were analyzed to discover the distribution of cited publications by type (e.g., monographs, journal articles). The median age of cited references (i.e., half-life) for each publication authored by Turkish arts and humanities scholars also was calculated. The term "half-life" is defined as "the time 


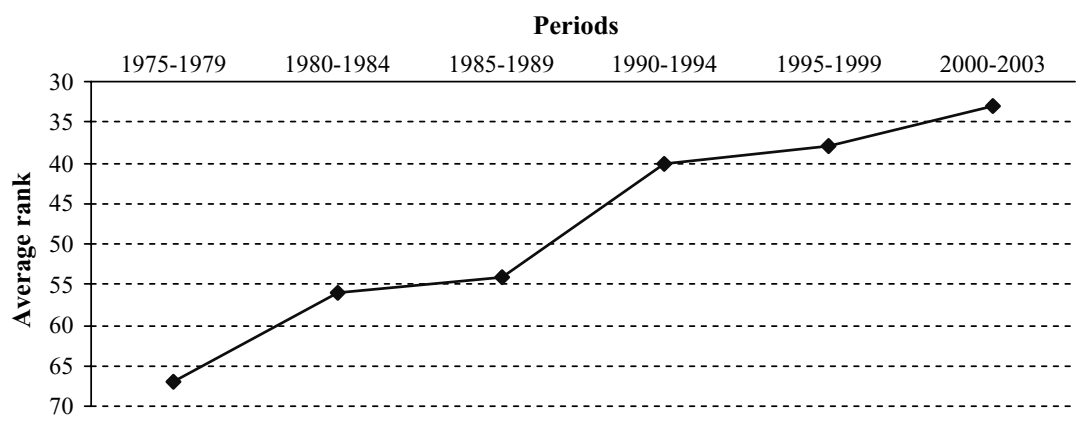

FIG. 1. Average rank of Turkey in the world's arts and humanities literature (1975-2003).

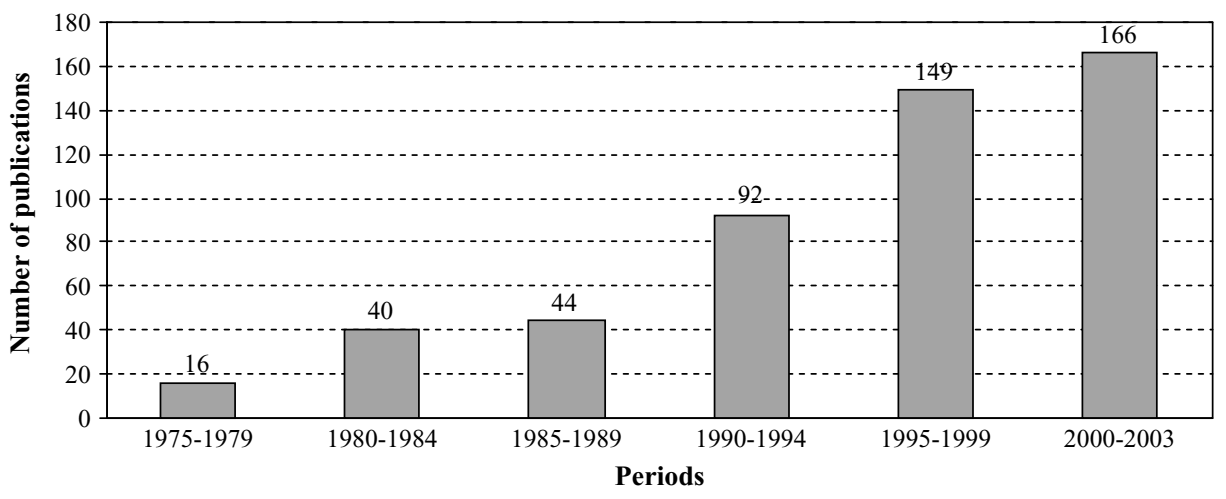

FIG. 2. Number of publications with Turkish addresses in the $A \& H C I$ database $(N=507)$.

during which one-half of the currently active literature was published" (Line, 1970, p. 46). Publications of the Turkish arts and humanities scholars that were cited at least once in the literature were identified along with self-citations. The time span between the publication date and the first citation date was calculated for each publication that received at least one citation.

\section{Results}

As indicated earlier, there were 507 publications indexed in the A\&HCI between 1975-2003. This figure constitutes approximately a mere $0.016 \%$ of the total publications in the arts and humanities literature of the world for the same period. ${ }^{1}$ According to data gathered by the Turkish Academic Network and Information Center, Turkey ranked 73rd in 1975 in the world in the arts and humanities literature and 36th in the year 2002 (TÜBİTAK, 2003). Figure 1 shows the gradual rise of Turkey's average rank in 5-year periods (except the last period that provides the average of 4 years, i.e., 2000-2003).

Figure 2 displays the number of arts and humanities publications contributed by authors based in Turkey. The number of publications did not increase much until the 1990s. A total of 100 publications were identified during the first 15 years (1975-1989), constituting only $20 \%$ of the total

${ }^{1}$ At the time of our search, the $A \& H C I$ database had indexed a total of $3,087,703$ publications. number of publications in this study. Yet, the number of publications has more than quadrupled (407) within the last 14 years (1990-2003), making up the remaining $80 \%$ of all publications under review. Consequently, the contribution of Turkish authors to the world's annual arts and humanities literature has increased from $0.046 \%$ in 1996 to $0.079 \%$ in 1999 and to $0.090 \%$ in 2002 (Tonta \& İlhan, 1997; TÜBITAK, 2003). Although the annual output seems to be rather low, the relatively high increase in the number of publications in the last decade or so is encouraging. The decision of the Turkish Higher Education Council to have publications listed in the $A \& H C I$ as one of the promotion criteria for scholars working for universities, along with the modest monetary support of the Turkish Academy of Sciences to such scholars, seems to have had a positive impact on the increase of the number of arts and humanities publications in the 1990s.

The distribution of publications by their types is given in Table 1. Journal articles constituted $62.7 \%$ of all publications

TABLE 1. Distribution of publications by types $(N=507)$.

\begin{tabular}{lrr}
\hline Publication type & $N$ & $\%$ \\
\hline Article & 318 & 62.7 \\
Book Review & 115 & 22.7 \\
Meeting Abstract & 26 & 5.1 \\
Note & 14 & 2.8 \\
Others & 34 & 6.7 \\
Total & 507 & 100.0 \\
\hline
\end{tabular}


while book reviews made up an additional $22.7 \%$ of all publications. Publications classified under the "Other" category (i.e., theater reviews, film reviews, art exhibit reviews, poetry, editorial materials, letters, corrections, additions, fiction, creative prose, and biographical items) constituted the remaining $6.7 \%$ of all publications. The great majority of all publications (91\%) were written in English. German (4.3\%), French $(3.1 \%)$, and Russian (1\%) followed the English language. Heinzkill (1980) reported similar results for cited items in English literary journal articles (91\% in English).

In an earlier study, Tonta and İlhan (1997) found that the percentage of journal articles contributed by social scientists affiliated with Turkish institutions and indexed in the SSCI was $76 \%$ while book reviews was a mere $6 \%$. Figures in Table 1 suggest that book reviews are indeed a more important type of publication in the arts and humanities than that in social sciences, verifying the findings of Garfield (1982a), Stern (1983), and Lindholm-Romantschuk and Warner (1996) regarding the "book-oriented nature" of arts and humanities.

Book reviews as a publication type may not necessarily reflect the real productivity of the Turkish arts and humanities scholars due to language, availability, and accessibility of the reviewed items. It is likely that the $A \& H C I$ would prefer to index book reviews written for books published in the English language rather than in other languages. In addition to the language barrier, arts and humanities scholars based in Turkey would be in a disadvantageous position to obtain these books in a timely manner to review and then submit their reviews to scholarly journals. For instance, we identified 98 book reviews in the $A \& H C I$ written by authors affiliated with Turkish institutions between 1994-2001. Yet, 36 of those book reviews were written by foreign scholars affiliated with Turkish institutions. An additional 20 book reviews were written by Talat Sait Halman, an eminent professor, author, and poet. In other words, a total of 42 book reviews (an average of four book reviews per year) were contributed by the remaining Turkish arts and humanities scholars. Compare this with the figures for Wales, a small country speaking both Welsh and English. We identified 2,822 book reviews written by Welsh scholars for the same period. $^{2}$

On the other hand, book reviews are not as heavily weighted as that of original journal articles in the Turkish academic system, which may further limit the number of such contributions by Turkish arts and humanities scholars.

Publications authored by Turkish arts and humanities scholars appeared in 230 different journals. More than half of the publications were published in 40 different journals while the remaining half appeared in 190 journals. There were 20 journals publishing five or more contributions by Turkish authors. Some 38\% (190 publications) of all publications appeared in those 20 journals listed in Table 2.

\footnotetext{
${ }^{2}$ Figures reported here were obtained from the $A \& H C I$ database. The search was performed on November 12, 2004.
}

TABLE 2. Journals publishing five or more contributions by Turkish authors.

\begin{tabular}{lrr}
\hline \multicolumn{1}{c}{ Journal name } & $N$ & $\%$ \\
\hline American Journal of Archaeology & 34 & 6.7 \\
World Literature Today & 26 & 5.1 \\
Antiquity & 12 & 2.4 \\
Muslim World & 10 & 2.0 \\
American Studies International & 9 & 1.8 \\
Journal of Economic History & 9 & 1.8 \\
Asian Folklore Studies & 8 & 1.6 \\
International Journal of Middle East Studies & 8 & 1.6 \\
Degres-Revué de Synthesé A Orientation Semiologiqué & 8 & 1.6 \\
Bulgarian Historical Review (Revué Bulgare D'Histoire) & 7 & 1.4 \\
Journal of Archeological Science & 7 & 1.4 \\
Arts of Asia & 7 & 1.4 \\
Theatre Journal & 7 & 1.4 \\
Journal of American History & 6 & 1.2 \\
Journal of Pragmatics & 6 & 1.2 \\
Comparative Studies in Society and History & 6 & 1.2 \\
TLS (The Times Literary Supplement) & 5 & 1.0 \\
Journal of Near Eastern Studies & 5 & 1.0 \\
Archaeometry & 5 & 1.0 \\
Journal of the Society of Architectural Historians & 5 & 1.0 \\
\hline
\end{tabular}

The most recurrent journal was the American Journal of Archaeology, publishing 34 contributions by Turkish authors. This journal is followed by World Literature Today, Antiquity, and Muslim World, respectively. Almost one fourth (124) of all publications were published in the first nine journals.

The distribution of the number of publications that appeared in journals and indexed in the $A \& H C I$ is given in Table 3 and Figure 3. The first one third (i.e., 33.5\%) of all publications appeared in 16 different arts and humanities journals, the next one third appeared in 59 different journals, and the last one third appeared in 155 different journals. The number of journals in which only one contribution by Turkish authors appeared amounted to $61.3 \%$ (or 141) of all journal titles. It appears that the scatter of publications by

TABLE 3. The number of publications by Turkish authors that appeared in the arts and humanities journals.

\begin{tabular}{ccccc}
\hline $\begin{array}{l}\text { No. of } \\
\text { journals }\end{array}$ & $\begin{array}{c}\text { No. of } \\
\text { publications }\end{array}$ & $\begin{array}{c}\text { Total no. of } \\
\text { publications }\end{array}$ & $\begin{array}{c}\text { Cumulative no. } \\
\text { of journals }\end{array}$ & $\begin{array}{c}\text { Cumulative } \\
\text { percentage of } \\
\text { all publications }\end{array}$ \\
\hline 1 & 34 & 34 & 1 & 6.7 \\
1 & 26 & 26 & 2 & 11.8 \\
1 & 12 & 12 & 3 & 14.2 \\
1 & 10 & 10 & 4 & 16.2 \\
2 & 9 & 18 & 6 & 19.7 \\
3 & 8 & 24 & 9 & 24.5 \\
4 & 7 & 28 & 13 & 30.0 \\
3 & 6 & 18 & 16 & 33.5 \\
4 & 5 & 20 & 20 & 37.5 \\
11 & 4 & 44 & 31 & 46.2 \\
16 & 3 & 48 & 47 & 55.6 \\
42 & 2 & 84 & 89 & 72.2 \\
141 & 1 & 141 & 230 & 100.0 \\
Total 230 & & 507 & & \\
\hline
\end{tabular}




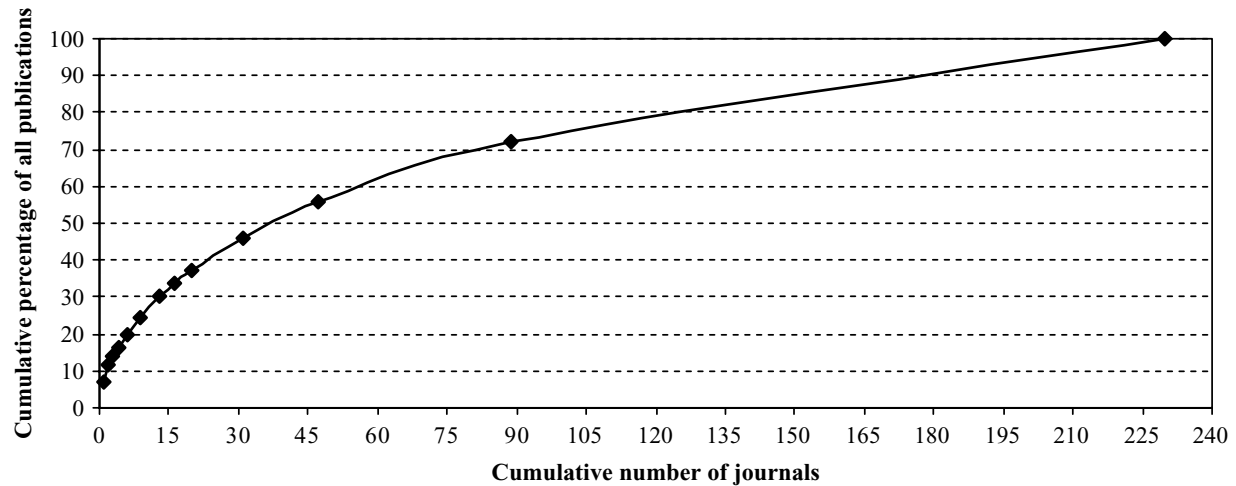

FIG. 3. Distribution of the number of publications by Turkish authors that appeared in the arts and humanities journals.

Turkish arts and humanities scholars does not conform to the traditional Bradford curve, suggesting that a "core literature is less clearly delineated" (Hicks, 2004, p. 473).

The great majority $(83 \%)$ of publications had single authorship. The general tendency is toward single authorship. This shows that contrary to researchers in biomedicine or physics in which multiple authorship is the norm, the arts and humanities scholars like solitary work, and they do their own research (Buchwald, 1999).

Publications with multiple authors constituted only $17 \%$ of all publications. There were 53 publications with two authors, 15 with three authors, and 7 with four authors. Only 9 publications had five or more authors. The highest number of contributors to a single publication was 10 . Nevertheless, we observed a small tendency toward multiple authorship in the arts and humanities literature. The percentage of publications with multiple authors was $12 \%$ in the second half of 1970 s whereas the ratio has risen to $22 \%$ in recent years. The average number of authors per publication rose from 1.19 to 1.37. This increase may be interpreted as a sign of a more collaborative and project-oriented research that is taking place in the arts and humanities fields in recent years. Yet, the figures of multiple-authorship rate and average number of authors per publication in the arts and humanities were indeed quite low compared to, say, those of biomedical publications (i.e., 95\% multiple-authorship rate and an average of 4.1 authors per publication) authored by Turkish scientists (Tonta, 2000).

The total number of different authors contributing to 507 publications was 422 (Table 4). Ten percent of all publications were produced by the five most prolific authors while a quarter of all publications were produced by 24 different authors. Three fourths ( $n=318$ ) of all authors contributed to the literature with only a single publication, which amounted to $47.7 \%$ of all publications. The overwhelming majority (90\%) of authors were affiliated with Turkish universities. In fact, more than half (57\%) of the contributing authors came from Bilkent, Bosphorus, and the Middle East Technical Universities (Table 5).

The total number of references included in the 507 publications was 9,789 (average per publication $=19$ ). More than half of all publications listed eight or more references. Ten percent of the arts and humanities publications contained no references. Journal articles contained relatively more references (average $=26$ references). More than half of all articles cited 20 or more references while $5 \%$ did not cite any references. Journal articles comprising more than $60 \%$ $(n=318)$ of all publications contained more than $85 \%$ $(n=8,327)$ of all references.

References listed in the 331 source publications (almost $60 \%$ of all publications) that appeared between 1994 and 2003 were analyzed to discover if monographs or journal articles were cited more heavily by the Turkish arts and

TABLE 4. Distribution of publications by number of contributing authors.

\begin{tabular}{rccc}
\hline $\begin{array}{l}\text { No. of } \\
\text { authors }\end{array}$ & $\begin{array}{c}\text { No. of different } \\
\text { publications they } \\
\text { contributed to }\end{array}$ & $\begin{array}{c}\text { Cumulative no. } \\
\text { of authors }\end{array}$ & $\begin{array}{c}\text { Cumulative } \\
\text { percentage of } \\
\text { all publications }\end{array}$ \\
\hline 1 & 20 & 1 & 3.0 \\
1 & 15 & 2 & 5.2 \\
2 & 11 & 4 & 8.5 \\
1 & 10 & 5 & 10.0 \\
1 & 8 & 6 & 11.2 \\
2 & 7 & 8 & 13.3 \\
4 & 6 & 12 & 16.9 \\
6 & 5 & 24 & 21.3 \\
6 & 4 & 46 & 25.0 \\
22 & 3 & 104 & 34.9 \\
58 & 2 & 422 & 52.3 \\
318 & 1 & & 100.0 \\
\hline
\end{tabular}

TABLE 5. The most prolific universities in A\&HCI.

\begin{tabular}{lrr}
\hline University name & $N$ & $\%$ \\
\hline Bilkent & 141 & 26.6 \\
Bosphorus & 94 & 17.7 \\
METU & 68 & 12.8 \\
Ankara & 34 & 6.4 \\
İstanbul & 31 & 5.9 \\
ITU & 18 & 3.4 \\
Hacettepe & 16 & 3.0 \\
Others & 128 & 24.2 \\
Total & 530 & 100.0
\end{tabular}

Note. The total is 530 , rather than 507 , due to multiple authorships. 
humanities scholars. An analysis of $70 \%(n=6,826)$ of all references contained in 331 source publications showed that two thirds $(n=4,525)$ of the references were to monographs and other publications while one third $(2,301)$ were to journal articles. Six review articles contained 20\% $(n=466)$ of all references to journal articles, which decreases the weight of the impact of journal articles even further (i.e., 27\% of all references). These figures clearly indicate that monographs have much greater importance in the arts and humanities literature, further reinforcing the findings of previous studies reported earlier (e.g., Broadus, 1971; Cullars, 1992; Heinzkill, 1980; Stern, 1983).

The publication years of references contained in the arts and humanities sources ranged between 1549 and 2003. ${ }^{3}$ Half the references were 12 years old or younger (Figure 4). The number of sources that were cited in the same year as they were published was only 50 (or $0.6 \%$ of all references). References that were 2 years old or younger constituted about $9 \%$ of all references in the source publications. Arts and humanities sources that were 3 or 4 years old were the most heavily cited ones by the Turkish scholars. Sources that were 5 years old or younger constituted $24 \%$ of all references while 26 years old or younger ones constituted $75 \%$.

Our findings indicate that publications in the arts and humanities tend to get aged more slowly than those in the sciences and social sciences (see Cullars, 1992; Heinzkill, 1980). In other words, arts and humanities publications continue to get cited long after they are published, a finding that should be taken into account by collection-development librarians when they "de-select" sources for off-campus storage or for disposal.

The impact of publications that were authored by the Turkish arts and humanities scholars was analyzed by

\footnotetext{
${ }^{3}$ Some $14 \%$ of all references contained in the arts and humanities source publications lacked publication dates.
}

TABLE 6. Citation characteristics of publications contributed by Turkish authors.

\begin{tabular}{|c|c|c|c|c|c|c|}
\hline \multirow{2}{*}{$\begin{array}{l}\text { No. of } \\
\text { citations }\end{array}$} & \multicolumn{2}{|c|}{$\begin{array}{l}\text { Journal } \\
\text { articles }\end{array}$} & \multicolumn{2}{|c|}{$\begin{array}{l}\text { Monographs and } \\
\text { others (e.g., book } \\
\text { reviews, notes) }\end{array}$} & \multicolumn{2}{|c|}{ Total } \\
\hline & $N$ & $\%$ & $N$ & $\%$ & $N$ & $\%$ \\
\hline 0 & 234 & 73.6 & 174 & 92.1 & 408 & 80.5 \\
\hline 1 & 42 & 13.2 & 11 & 5.8 & 53 & 10.5 \\
\hline 2 & 11 & 3.5 & 0 & 0.0 & 11 & 2.2 \\
\hline 3 & 7 & 2.2 & 1 & 0.5 & 8 & 1.6 \\
\hline 4 & 6 & 1.9 & 1 & 0.5 & 7 & 1.4 \\
\hline 5 & 4 & 1.3 & 1 & 0.5 & 5 & 1.0 \\
\hline 6 & 5 & 1.6 & 0 & 0.0 & 5 & 1.0 \\
\hline$\geq 7$ & 9 & 2.8 & 1 & 0.5 & 10 & 2.0 \\
\hline Total & 318 & 100.1 & 189 & 99.9 & 507 & 100.2 \\
\hline
\end{tabular}

Note. Percentages may not equal $100 \%$ due to rounding.

checking the "Times cited" field that is available in the $A \& H C I$ database. As of November 12, 2003, we found that more than $80 \%(n=408)$ of all publications by Turkish authors received no citations (Table 6$)$. The rest $(n=99$; $19.5 \%$ of all publications) were cited at least once. The most frequently cited publication was cited 22 times. The number of publications that received seven or more citations was only 10. Journal articles appear to have a slightly higher probability of receiving any citations, as more than a one fourth of all journal articles were cited at least once.

A similar study investigating the citation rates of Turkish social scientists within a time span of 30 years (1970-1999) showed that $49 \%$ of publications received no citations (Gülgöz, Yedekçioğlu, \& Yurtsever, 2002, p. 113). It appears that the contributions of Turkish social scientists have a higher probability of receiving any citations than those of Turkish arts and humanities scholars.

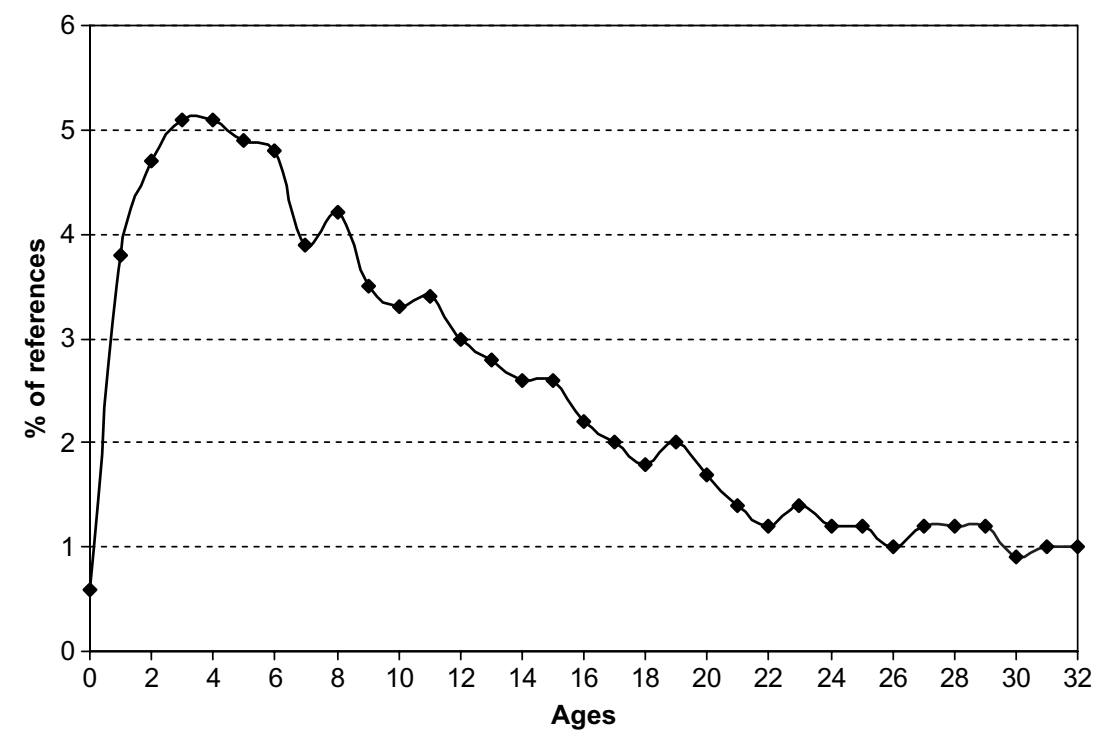

FIG. 4. Ages (in years) of the references contained in the arts and humanities source publications (not all years are included) $(N=8,390)$. 


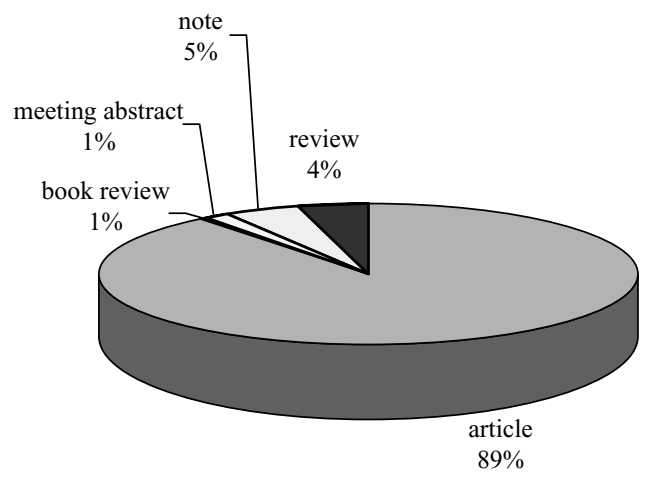

FIG. 5. Distribution of citations by publication types (No. of publications $=$ 99, No. of citations $=304)$.

The distribution of 99 publications that were authored by Turkish arts and humanities scholars and cited at least once is as follows: 84 journal articles, 5 notes, 4 meeting abstracts, 4 review articles, and 2 book reviews. Ninety-nine publications were cited a total of 304 times. Journal articles received the overwhelming majority $(89 \%)$ of all citations, followed by notes $(5 \%)$ and reviews (4\%) (Figure 5). The self-citation ratio was $31 \%$. Journal articles, review articles, and notes were cited, on average, about three times while book reviews and meeting abstracts were cited once.

Table 7 shows the number of years (ages) that cited publications received their first citations. Some $11 \%$ of the publications were cited within the year of their publication while $29 \%$ were cited after 1 year and an additional $23 \%$ after 2 years of publication. More than one third of all publications that received any citations were not cited within the first 2 years after they were published. Ninety percent of all cited publications received their first citations within the 6 years after they were published. A few publications received their first citations as long as 15 years after they appeared in print. Some publications were naturally cited more than once, and the time span between publication dates and citation dates was even longer than 15 years. For example,

TABLE 7. Ages of first citations $(N=99)$.

\begin{tabular}{crrr}
\hline Ages & & & $\begin{array}{c}\text { Cumulative percentage } \\
\text { of all cited publications }\end{array}$ \\
\hline 0 & $N$ & 11.1 & 11.1 \\
1 & 11 & 29.3 & 40.4 \\
2 & 29 & 23.2 & 63.6 \\
3 & 23 & 7.1 & 70.7 \\
4 & 7 & 6.1 & 76.8 \\
5 & 6 & 9.1 & 85.9 \\
6 & 9 & 4.0 & 89.9 \\
7 & 4 & 1.0 & 90.9 \\
8 & 1 & 3.0 & 93.9 \\
9 & 3 & 1.0 & 94.9 \\
10 & 1 & 2.0 & 97.0 \\
11 & 2 & 1.0 & 98.0 \\
12 & 1 & 1.0 & 99.0 \\
15 & 1 & 1.0 & 100.0 \\
Total & 1 & 100.0 & \\
\hline
\end{tabular}

three publications were cited after 21,23 , and 25 years of their publication.

De Solla Price (1970) noted long ago that scientific disciplines differ in terms of the percentages of references to the relatively recent (i.e., 5 years old) publications (known as the Price Index). Glänzel (1996) advised that citation-based indicators be interpreted cautiously in social sciences because "a decade long citation window would be needed to capture the slow accumulation of citations" (Hicks, 2004, p. 474). This is even more important in the arts and humanities because it usually takes much longer for a publication to get cited. The percentages that we obtained clearly indicate that a 2-year window used by the ISI to calculate the impact of a given publication (in sciences as well as in social sciences and humanities) is not enough for arts and humanities publications. More than one third of all cited publications get cited after 2 years of their publication dates. Our findings strongly suggest that the citation-based performance evaluation of the arts and humanities scholars would be unfair and put them in a disadvantageous position in comparison with their colleagues in the sciences and social sciences.

In addition, we investigated which journals have accommodated the most frequently cited publications. We found that publications appeared in seven (i.e., World Literature Today, Degres-Revué de Synthesé A Orientation Semiologiqué, Bulgarian Historical Review-Revué Bulgare D'Histoire, Arts of Asia, Theatre Journal, TLS, Journal of the Society of Architectural Historians) of the 20 journals presented in Table 2 received no citations. On the other hand, seven publications that appeared in the Journal of Archeological Science received a total of 36 citations, an average of 5.14 citations per publication. This is followed by Antiquity and Archaeometry, with average rates of 2.75 and 2.20 citations per publication, respectively. The average citation rates of the remaining 10 journals were between 0.11 and 1.38 . It appears that publications in archeology enjoyed relatively higher number of citations. The most frequently cited article (22 times) appeared in the Journal of Field Archaeology. If citation rates are of any significance, these findings seem to indicate that Turkish archeologists have been quite prolific in the international literature and that their contributions have been relatively well regarded by their colleagues.

\section{Discussion}

Our findings indicate that the characteristics of the arts and humanities literature are rather different than those of the sciences and social sciences. It seems clear that care should be exercised when using citation data for performance evaluation of arts and humanities scholars.

Although the criteria (i.e., timeliness of publication; English language titles, abstracts and keywords; peer review; international diversity; and citation analysis) for adding the sources into citation indexes including the $A \& H C I$ are the same, the number of journals being published and hence being indexed by the ISI in different fields varies. Currently, the $A \& H C I$ has only 1,132 arts and humanities journals 
indexed while the $S S C I$ has 1,805 , the $S C I$ has 3,733 , and the SCI-Expanded has 6,357 journals indexed in their respective fields (http://scientific.thomson.com/mjl/). Some 91 journal titles are indexed by both the $A \& H C I$ and the SSCI. The $A \& H C I$ indexes some 50,000 articles annually whereas the $S C I$ does more than 1 million articles. Consequently, it takes much longer for an article in the arts and humanities "to attract a meaningful number of citations" (ISI, 2005a). Moreover, the A\&HCI's coverage of non-Western and nonEnglish literature is rather scant. Almost two thirds of all journals indexed in the $A \& H C I$ are of North American and United Kingdom origin. Very few journals published outside the United States and Europe get indexed by the A\&HCI, "which tends to deflate their citation counts" (Garfield, 1982b, p. 7).

The ISI (2005a) acknowledged that citation data in the arts and humanities are much less useful in journal evaluations due to the fact that citations do not necessarily follow predictable patterns:

Citations to an article on the 19th Century Romantic novel, for example, may accrue slowly at first, and then slacken, fluctuating over time in cycles consistent with scholars' varying interest in the topic. In addition, Arts and Humanities journal articles reference nonjournal sources heavily (e.g., books, musical compositions, works of art and literature).

Earlier, we discussed the importance of books and book reviews in the arts and humanities literature, and provided detailed data regarding the types of material cited along with their ages. Line (1979) obtained similar findings for references contained in journals and monographs in social sciences and alluded to the fact that "monographs may be used as a vehicle for new knowledge in the social sciences" (p. 282), which is equally applicable to monographs in the arts and humanities. Yet, the ISI treats nonjournal sources cited in the arts and humanities journal articles somewhat differently and considers more than $70 \%$ of them as "noncitable" items ("Noncitable" items constitute $22 \%$ of all items in the SCI and 46\% in the SSCI.) (Jacsó, 2001, p. 591). In other words, more than $70 \%$ of the items indexed in the $A \& H C I$ are not taken into account when calculating the impact factors for the $A \& H C I$ journals. The existence of comparatively more "noncitable" items in the arts and humanities journal articles also may be interpreted as an indication of the fact that arts and humanities fields usually lack core journals. Furthermore, less than $20 \%$ of citations in social sciences and humanities journal articles match against an ISI journal citation database while a "journal in molecular biology will have rates in excess of 90\%" (Garfield, 1979, p. 32). In other words, the ISI fails to index the contents of a considerable number of arts and humanities journals, which can be verified through the WoS: Very few references at the end of articles listed in the $A \& H C I$ tend to have "live" links to other journal titles.

Garfield (1979) thought at the beginning that the $A \& H C I$ would "revolutionize scholarship" and maintained that "[b]eing cited is already considered an important mark of scholarship in the humanities, so there is reason to believe that scholars in that area will find formal citation measurements more acceptable" (pp. 240-241). Garfield (1980a, 1982b) even planned to publish the Journal Citation Reports (JCRs) for the $A \& H C I$ in the early days. JCRs provide quantifiable statistical data about journal titles and enable users to sort data by various fields such as journal impact factor and cited half-life (ISI, 2005b). Garfield (1980a) hoped that JCRs for the $A \& H C I$ would "help librarians build or prune collections" in the arts and humanities fields (p. 55); however, JCRs for the $A \& H C I$ had never been materialized. It was realized that citation characteristics of arts and humanities journal articles were quite different than those of the sciences and social sciences. For instance, less than $10 \%$ of all citations in the art journals were to the current literature, and thus their "immediacy index" was quite low compared to much higher percentages recorded in the sciences and social sciences (60-70\% and 46.5\%, respectively) (Garfield, 1979, p. 72). One is tempted to speculate that the ISI had after all decided not to publish JCRs for the $A \& H C I$ in view of the potential problems using JCRs as a tool for journal and performance evaluation purposes in the arts and humanities.

It follows from the aforementioned discussion that the $A \& H C I$ may not be the most appropriate source to use to evaluate the performance of Turkish arts and humanities scholars, nor can their performance be measured based solely on the number of articles or book reviews they write or the number of citations their contributions are likely to receive in the arts and humanities journal literature.

\section{Conclusion}

Turkey's contribution to the world's arts and humanities literature has increased significantly during the recent years. The quantitative increase in Turkey's contribution to the arts and humanities literature can be attributed partly to the increasing awareness by the academic environment of the significance of international publications (especially journal articles) due to the Turkish Higher Education Council's regulations put forward in the mid-1990s, partly to the encouragement of the Turkish Academy of Sciences and partly to the increase in the number of academic personnel who, at certain stages of their career, have studied abroad.

That more than $60 \%$ of contributions by the arts and humanities scholars based mainly in Turkish universities were in the form of journal articles is encouraging. On the other hand, very few book reviews were contributed by the Turkish authors. Contributions by Turkish scholars were published in relatively few journal titles, although it is difficult to identify a "core" journal list in the arts and humanities literature. The single authorship was prevalent (83\%). One fourth of all publications were authored by relatively few $(n=24)$ prolific scholars while the remaining $75 \%$ were contributed to by 398 different scholars. References to monographs constituted two thirds of all references contained in the bibliographies of arts and humanities publications. The median 
age of all references was 12 years. Publications in the arts and humanities get cited over longer periods of time and age more slowly than those in the sciences and social sciences. The great majority of publications authored by the Turkish arts and humanities scholars seem to have been neglected by other scholars, and they received no citations. Contributions by Turkish scholars received just over 300 citations (one third of which were self-citations) in almost 30 years. The average number of citations per journal article was just over three citations, although the Turkish archeologists seem to have enjoyed higher citation rates than their colleagues publishing in other subject specialties. Almost two thirds of the cited publications get their first citations within the first 2 years of their publication. Citation-based performance measures in the arts and humanities literature should be used with caution, as citations tend to accumulate in a longer period of time. Library and information centers should keep longer runs of back issues of arts and humanities journals, as they tend to get cited long after they were published.

Our work illustrates that monographs are the primary medium of scholarly communication, and publications tend to obsolesce more slowly in the arts and humanities. Publications are scattered over a relatively large number of journals. More contributions from the arts and humanities scholars based in Turkey are required. These contributions should be published in the journals with high citation-impact factors to elicit more citations. This is especially important because only one fifth of all publications authored by Turkish arts and humanities scholars were ever cited by other researchers while one third of those were selfcitations. Further research is needed to create a profile of the Turkish arts and humanities literature based on bibliometric and citation characteristics of such contributions.

\section{Acknowledgment}

Comments and suggestions of an anonymous referee are gratefully acknowledged.

\section{References}

Braun, T., Glänzel, W., \& Grupp, H. (1995a). The scientometric weight of 50 nations in 27 science areas, 1989-1993. Part I: All fields combined, mathematics, engineering, chemistry and physics. Scientometrics, 33(3), 263-293.

Braun, T., Glänzel, W., \& Grupp, H. (1995b). The scientometric weight of 50 nations in 27 science areas, 1989-1993. Part II: Life sciences. Scientometrics, 34(2), 207-237.

Broadus, R.N. (1971). The literature of the social sciences: A survey of citation studies. International Social Sciences Journal, 23, 236-243.

Buchwald, N. (1999). Thinking of information through the humanist's eyes. Retrieved August 11, 2004, from http://www.library.arizona.edu/users/ buchwaln/humanities.html

Cullars, J. (1992). Citation characteristics of monographs in the fine arts. Library Quarterly, 62, 325-342.

Denkel, A., Kâğıtçıbaşı, Ç., Pak, N.K., \& Pamuk, Ş. (1996). Uluslararası atıf endeksleri verilerine göre Türkiye'de sosyal bilimlerin yayın performans1 [Publication performance of Turkey in social sciences according to international citation indexes data]. Report prepared for TÜBA.
Denkel, A., Kâğıtçıbaşı Ç., Pak, N.K., \& Pamuk,Ş. (1999). Türkiye'de sosyal bilimlerin uluslararası yayın performansı [International publication performance of Turkey in social sciences]. Ankara, Turkey: TÜBA.

de Solla Price, D.J. (1970). Citation measures of hard science, soft science, technology and non-science. In C.E. Nelson \& D.K. Pollack (Eds.), Communication among scientists and engineers (pp. 1-12). Lexington, MA: Heat.

Finkenstaedt, T. (1980). Measuring research performance in the humanities. Scientometrics, 19(5-6), 409-417.

Garfield, E. (1979). Citation indexing-Its theory and application in science, technology, and humanities. Philadelphia: ISI Press. Retrieved May 2, 2005, from http://www.garfield.library.upenn.edu/ci/title.pdf

Garfield, E. (1980a). Is information retrieval in the arts and humanities inherently different from that in science? The effect that ISI's citation index for the arts and humanities is expected to have on future scholarship. Library Quarterly, 50, 40-57.

Garfield, E. (1980b, May 12). Bradford's law and related statistical patterns. Current Contents, 19, 5-12.

Garfield, E. (1982a). Journal citation studies, 38. Arts and humanities journals differ from natural and social sciences journals-but their similarities are surprising. Current Contents, 47, 5-11. Retrieved April 27, 2004, from http://www.garfield.library.upenn.edu/essays/v5p761y 1981-82.pdf

Garfield, E. (1982b, November 15). Data from Arts \& Humanities Citation Index reveal the interrelationships of science and humanities. Current Comments, 46, 5-7. Retrieved May 2, 2005, from http://www.garfield. library.upenn.edu/essays/v5p758y1981-82.pdf

Garfield, E. (1983). Mapping science in the third world. Science and Public Policy, 10(3), 112-127. Retrieved April 12, 2004, from http://www.garfield. library.upenn.edu/papers/mapscithirdworldp112y1983.pdf

Garfield, E. (1991). A citationist perspective on science in Turkey. Tip alanında bilimsel yayınlar sempozyumu [In Symposium on scientific publications in medical sciences] (pp. 8-40). Ankara, Turkey: TÜBİTAK.

Glänzel, W. (1996). A bibliometric approach to social sciences. National research performances in six selected social science areas, 1990-1992. Scientometrics, 35(3), 291-307.

Gülgöz, S., Yedekçioğlu, Ö.A., \& Yurtsever, E. (2002). Turkey's output in social science publications: 1970-1999. Scientometrics, 55(1), 103-121.

Haiqi, Z., \& Yuhua, Z. (1997). Scientometric study on research performance in China. Information Processing \& Management, 33(1), 81-89.

Heinzkill, R. (1980). Characteristics of references in selected scholarly English literary journals. Library Quarterly, 50, 352-365.

Hérubel, J.-P.V.M., \& Buchanan, A.L. (1994). Citation studies in the humanities and social sciences: A selective and annotated bibliography. Collection Management, 18(3-4), 89-137.

Hicks, D. (2004). The four literatures of social science. In H.F. Moed, W. Glänzel, \& U. Schmoch (Eds.), Handbook of quantitative social science and technology research (pp. 473-496). Dordrecht, The Netherlands: Kluwer. Retrieved August 13, 2004, from http://www.tpac.gatech. edu/papers/4lit.PDF

İnönü, E. (2003). The influence of cultural factors on scientific production. Scientometrics, 56(1), 137-146.

İnönü, E., \& Kurnaz, L. (2002). Observations on the growth characteristics of the research output of Turkish physicists based on selective citation analysis. Scientometrics, 55(3), 437-444.

ISI. (2004a). Thomson ISI: Citation products. Retrieved June 15, 2004, from http://www.isinet.com/cit/

ISI. (2004b). Thomson ISI: Arts and Humanities Citation Index. Retrieved October 25, 2004, from http://www.isinet.com/products/citation/ahci/ ISI. (2004c). Cited reference searching in the Arts and Humanities Citation Index. Retrieved September 22, 2004, from http://sunweb.isinet.com/ tutorials/citedreference/crs14.htm\#muscat_highlighter_first_match

ISI. (2004d). Glossary. Retrieved September 22, 2004, from http://sunweb. isinet.com/glossary/\#muscat_highlighter_first_match

ISI. (2005a). The ISI® Database: The Journal Selection Process. Retrieved April 27, 2005, from http://www.isinet.com/essays/selectionofmaterial forcoverage/199701.html/ 
ISI. (2005b). Journal Citation Reports. Retrieved May 3, 2005, from http://www.isinet.com/products/evaltools/jcr/

Jacobs, D., \& Ingwersen, P. (2000). A bibliometric study of the publication patterns in the sciences of South African scholars 1981-96. Scientometrics, 47(1), 75-93.

Jacsó, P. (2001, September). A deficiency in the algorithm for calculating the impact factor of scholarly journals: The journal impact factor. Cortex, 37(4), 590-594. Retrieved May 3, 2005, from http://www.hooklee.com/ Research/Deficiency_Impact_Factor.pdf

Lindholm-Romantschuk, Y., \& Warner, J. (1996). The role of monographs in scholarly communication: An empirical study of philosophy, sociology and economics. Journal of Documentation, 52, 389-404.

Line, M.B. (1970). The "half-life" of periodical literature: Apparent and real obsolescence. Journal of Documentation, 26, 46-54.

Line, M.B. (1979). The influence of the type of sources used on the results of citation analyses. Journal of Documentation, 35, 265-284.

MacRoberts, M.H., \& MacRoberts, B.R. (1989). Problems of citation analysis: A critical review. Journal of the American Society for Information Science, 40, 342-349.

Moed, H.F. (2002). Measuring China's research performance using the Science Citation Index. Scientometrics, 55(3), 281-296.

Moed, H.F., De Bruin, R.E., \& Van Leeuwen, N. (1995). New bibliometric tools for the assessment of national research performance: Database description, overview of indicators and first applications. Scientometrics, 33(3), 381-422.

Nederhof, A.J., Luwel, M., \& Moed, H.F. (2001). Assessing the quality of scholarly journals in linguistics: An alternative to citation-based journal impact factors. Scientometrics, 51(1), 241-265.

Nederhof, A.J., \& Zwaan, R.A. (1991). Quality judgements of journals as indicators of research performance in the humanities and the social and behavioural sciences. Journal of the American Society for Information Science, 42, 332-340.

Nederhof, A.J., Zwaan, R.A., De Bruin, R.E., \& Dekker, P.J. (1989). Assessing the usefulness of bibliometric indicators for the humanities and the social and behavioural sciences: A comparative study. Scientometrics, 15(5-6), 423-435.

Ortiz-Rivera, L.A., Sanz Casado, E., \& Suárez-Balseiro, C.A. (2000). Scientific production in Puerto Rico in science and technology during the period 1990 to 1998. Scientometrics, 49(3), 403-418.

Osareh, F., \& Wilson, C.S. (2000). A comparison of Iranian scientific publications in the Science Citation Index: 1985-1989 and 1990-1994. Scientometrics, 48(3), 427-442.

Stern, M. (1983). Characteristics of the literature of literary scholarship College \& Research Libraries, 44, 199-209.

Tonta, Y. (2000). Contribution of Turkish researchers to the world's biomedical literature (1988-1997). Scientometrics, 48(1), 71-84.

Tonta, Y. \& İlhan, M. (1997). Sosyal bilimlerde Türkiye'nin dünyadaki yeri [Turkey's place in social sciences in the world]. Türk Psikoloji Dergisi, 12(40), 67-75.

TÜBITTAK. (2003). Web of Science atıf indeksleri yayın sayıları [Number of publications in Web of Science citation index]. Retrieved November 15, 2003, from http://sciserv.ulakbim.gov.tr/wos/

Uzun, A. (1996). A bibliometric analysis of physics publications from Middle Eastern Countries. Scientometrics, 36(2), 259-269.

Uzun, A. (1998). A scientometric profile of social sciences research in Turkey. International Information and Library Review, 30, 169-184.

Uzun, A., \& Özel, M.E. (1996). Publication patterns of Turkish astronomers. Scientometrics, 37(1), 159-169.

Wilson, C.S., \& Osareh, F. (2003). Science and research in Iran: A scientometric study. Interdisciplinary Science Reviews, 28(1), 26-37.

Yurtsever, E., Gülgöz, S., Yedekçioğlu, Ö.A., \& Tonta, M. (2001). Sosyal Bilimler Atıf Dizini'nde (SSCI) Türkiye: 1970-1999 [Turkey in the Social Science Citation Index: 1970-1999]. Ankara, Turkey: TÜBA.

Yurtsever, E., Gülgöz, S., Yedekçioğlu, Ö.A., \& Tonta, M. (2002). Sağlık bilimleri, mühendislik ve temel bilimlerde Türkiye'nin uluslararası atıf dizinindeki yeri: 1973-1999 [Turkey's place in the international citation index in medical sciences, engineering and pure sciences: 1973-1999]. Ankara, Turkey: TÜBA. 